\title{
СЦЕНАРИИ РАЗВИТИЯ ПРОИЗВОДСТВА ЗЕРНА И СОСТОЯНИЯ ЗЕРНОВОГО РЫНКА В КРАТКО- И СРЕДНЕСРОЧНОЙ ПЕРСПЕКТИВЕ *
}

\author{
(c) 2020 Зюкин Данил Алексеевич \\ кандидат экономических наук \\ Курская Государственная сельскохозяйственная академия имени И.И. Иванова, Россия, Курск \\ E-mail: nightingale46@rambler.ru \\ (c) 2020 Солошенко Руслан Викторович \\ доктор экономических наук \\ Курская Государственная сельскохозяйственная академия имени И.И. Иванова, Россия, Курск \\ E-mail: soloshenko-v-m@yandex.ru
}

В статье рассматривается вопрос развития зернопродуктового подкомплекса АПК в контексте различных вариантов состояния внутреннего зернового рынка и объемов производства зерна. Сделан анализ предлагаемого в Стратегии долгосрочного развития зернового подкомплекса до 2035 года прогноза баланса зерна и выявлены его недостатки: линейный характер изменения валовых сборов и расхождение с объемом внутреннего потребления, что определяет недоучет масштабов ожидаемого экспорта в текущем и ближайшем сезоне. В исследовании анализируется текущее состояние, факторы, повлиявшие на него, и среднесрочные перспективы увеличения экспорта зерна. В статье предложен авторский прогноз вариаций экспорта в ближайший год в зависимости от 3 вариантов изменения внутреннего потребления и 6 вариантов изменения урожая зерна.

Ключевые слова: зернопродуктовый подкомплекс, зерновое хозяйство, производство зерна, внутреннее потребление, экспорт, сценарное прогнозирование, государственное регулирование, стратегия.

Продукция зернопродуктового подкомплекса АПК составляет основу агропродовольственного рынка России, так как определяет уровень хлебофуражного снабжение населения. Поэтому стабильность функционирования агропродовольственного рынка и надежность продовольственного обеспечения требуют наличия четкой стратегии действий в зависимости от различных сценариев развития ситуации на российском зерновом рынке.

Ключевым показателем, который необходимо учитывать при стратегии развития зернопродуктового подкомплекса АПК, является уровень валовых сборов зерна, от которого зависят экспортный потенциал и обеспечение внутренних потребностей [3]. В России валовые сборы зерновых культур существенно увеличились относительно показателей прошлого десятилетия, стабильно превышая с 2014 года 100 млн. т. зерна. Однако стабильность урожаев остается невысокой: вариация показателя за десятилетие составила $18 \%$, а разница между самым урожайным годом (2017 год - 135 млн. т) и неудачным (2012 год - 70,9 млн. т) достигает 64,5 млн. т, что формирует значительную трудность в планировании развития зернопотребляющих отраслей и экспорта. В связи с этим применяется метод сценарного прогнозирования, в рамках которого формируются различные варианты развития событий и действия в зависимости от условий.

Различные сценарии развития приводятся в «Долгосрочной стратегии развития зернового комплекса Российской Федерации до 2025 и на перспективу до 2035 г.», которые предполагают оптимистичный, базовый и пессимистичный вариант валовых сборов зерна и балансов его использования [1]. В начальной стадии базовый и оптимистичный сценарии отличаются не значительно, а разница формируется в дальнейшем за счет более динамичного развития в оптимальных условиях. Пессимистичный сценарий изначально предполагает стартовые позиции существенно хуже и при дальнейшей меньшей динамике роста показателей. В итоге, на первой контрольной дате в 2025 году оптимистичный сценарий превышает показатели базовый сценария на 8,7 млн. т зерна по валовому сбору, на 5 млн. т по внутреннему потреблению и на 3 млн. т

\footnotetext{
" Статья подготовлена при финансовой поддержке РФФИ в рамках научного проекта № 18-310-00211
} 
по экспорту, тогда как пессимистичный уступает базовому 14,1 млн. т зерна в валовом сборе и на 14,6 млн. т по экспорту при равном внутреннем потреблении. В 2035 году разброс в показателях в зависимости от различных сценариев Стратегии развития зернового подкомплекса увеличится более значительно (таблица 1).

В Стратегии помимо зернового баланса в зависимости от сценариев развития зернового подкомплекса представлены ориентировочное распределение основных направлений формирования экспортных потоков зерна и основные географические зоны, куда будет осуществляться экспорт российского зерна при показателях базового сценария. Существенным недостатком, разработанного в Стратегии прогноза зернового баланса, является предположение линейного наращивания валовых сборов зерновых культур, что на практике не происходит. Например, в оптимистичном сценарии предполагается средний ежегодный прирост урожая зерна на уровне 3-3,1 млн. т зерна, а в базовом - 2,2-2,3 млн. т. В силу ряда специфических особенностей возделывания зерновых культур такой подход дает лишь весьма обобщенную оценку, которая может ориентировать только на выход на определенные показатели в стратегический период. Это, в свою очередь, будет определять потребности и задачи для соответствующего развития производственно-логистической инфраструктуры, формирования источников государственночастного финансирования, а также кредитнофинансовых учреждений.
В краткосрочном периоде прогнозные значения уже отличаются по размеру потребления зерна на внутреннем рынке, его экспорту и запасам, хотя по фактическому урожаю 2019 года прогноз сопоставим с оптимистичным сценарием в Стратегии (разница менее чем на 1 млн. т зерна). Ключевой ошибкой в Стратегии является недооценка развития внутреннего рынка потребления зерна в краткосрочной перспективе, которое оказалось ниже по пшенице в сравнении с предыдущим годом более чем на 3 млн. т, что, не смотря на рост потребления ячменя и кукурузы, повлекло сокращение потребления зерна (таблица 2).

На сокращение внутреннего потребления повлияло падение спроса на зерно со стороны животноводов: поголовье птицы уже в прошлом году стало сокращаться, а из-за роста цен на российском зерновом рынке оптимизируются расходы на комбикорма. Вторым фактором является сохранение тренда на здоровое питание, в рамках которого идет снижение потребления хлебобулочной продукции. Влияние этого тренда выше, чем сокращения реальных доходов населения, которое обычно приводит к росту спроса на более доступные хлебобулочные изделия. С учетом улучшения экономической ситуации в стране прекратилось падение реальных доходов населения, поэтому влияние парадигмы здорового питания будет и далее усиливаться, снижая спрос на продовольственное зерно на внутреннем зерновом рынке.

В этой связи резервом роста для внутрен-

Таблица 1. Прогноз основных параметров развития зернового подкомплекса России по ключевым датам периода 2018-2035 гг.

\begin{tabular}{|c|c|c|c|}
\hline $\begin{array}{c}\text { Сценарий развития } \\
\text { ситуации }\end{array}$ & $\begin{array}{c}\text { Валовой сбор зерновых, } \\
\text { млн. т }\end{array}$ & $\begin{array}{c}\text { Внутреннее потребление } \\
\text { зерна, млн. т }\end{array}$ & $\begin{array}{c}\text { Экспорт зерновых, } \\
\text { млн. т }\end{array}$ \\
\hline \multicolumn{4}{|c|}{2018 год } \\
\hline Оптимистичный & 118,3 & 82,1 & 52,0 \\
\hline Базовый & 115,1 & 82,4 & 50,0 \\
\hline Пессимистичный & 102,2 & 82,0 & 42,0 \\
\hline \multicolumn{4}{|c|}{2025 год } \\
\hline Оптимистичный & 139,5 & 92,0 & 46,7 \\
\hline Базовый & 130,8 & 87,0 & 43,7 \\
\hline Пессимистичный & 116,7 & 87,2 & 29,1 \\
\hline \multicolumn{4}{|c|}{2035 год } \\
\hline Оптимистичный & 169,8 & 105,2 & 63,9 \\
\hline Базовый & 153,5 & 92,7 & 60,6 \\
\hline Пессимистичный & 130,0 & 93,9 & 35,8 \\
\hline
\end{tabular}

Источник: составлено автором по данным Долгосрочной стратегии развития зернового комплекса Российской Федерации до 2025 и на перспективу до 2035 г [1] 
Таблица 2. Сопоставление фактических результатов зернового подкомплекса России в 2019 году с прогнозными показателями Стратегии

\begin{tabular}{|l|c|c|c|c|}
\hline \multirow{2}{*}{\multicolumn{1}{|c|}{ Показатель }} & Фактические & \multicolumn{3}{|c|}{ Сценарии в Стратегии } \\
\cline { 3 - 5 } & $\begin{array}{c}\text { значения в 2019 } \\
\text { году }\end{array}$ & Оптимистичный & Базовый & Пессимистичный \\
\hline Валовой сбор зерновых, млн. т & 120,7 & 105,3 & 117,4 & 121,3 \\
\hline Экспорт зерна, млн. т & 43,3 & 18,0 & 33,9 & 38,0 \\
\hline $\begin{array}{l}\text { Внутреннее потребление зерна, } \\
\text { млн. т }\end{array}$ & 78,4 & 83,0 & 83,4 & 83,1 \\
\hline
\end{tabular}

Источник: составлено автором по данным Долгосрочной стратегии развития зернового комплекса Российской Федерации до 2025 и на перспективу до 2035 г [1]

него потребления зерна является увеличение спроса мясо-молочной продукции или выход этой продукции на зарубежные рынки как стимул дальнейшего наращивания производства в животноводстве [4]. Для решения первой задачи принципиально важно обеспечить рост доходов малоимущих семей, чего достичь в краткосрочном периоде в России не получится без коренных экономико-политических изменений. Экспорт мяса пока только на начальном этапе и также ожидать быстрого прогресса весьма трудно, но на стратегический период такая задача ставится на самом высшем уровне власти.

Качество и стоимость комбикормов в животноводстве является важным фактором повышения конкурентоспособности отечественного мяса (в первую очередь, свинина имеет наибольший экспортный потенциал). Поэтому повышение качества зерна и совершенствование организации процессов его глубокой переработки, предполагаемые в рамках реализации Стратегии, окажут дополнительную поддержку экспорту как зерна, так и мяса. Для этих целей в Стратегии предполагается до 2035 года выделить 709 млрд. руб., в том числе на создание мощностей глубокой переработки зерна 150 млрд. руб. и 559 млрд. руб. на создание и модернизацию мощностей мукомольно-крупяной и комбикормовой промышленности [1]. Однако, в сравнении с предполагаемыми расходами на приобретение тракторов и комбайнов, финансирование проектов развития переработки в 4,7 раза меньше. Способствовать улучшению материально-технической базы зерносеющих организаций, безусловно, нужно, однако более эффективно для экономики страны будет выполнение этой задачи вместе с развитием отечественного производства сельскохозяйственной техники. В противном случае ситуация окажется как в системе здравоохранения, где закупленная в начале Национального проекта «Здоровья» импортная техника уже на финише своего срока эксплуатации, но полноценной замены отечественными аналогами в большинстве случаев нет, и по новому кругу начинается опять закупка импортной техники.

Несмотря на то, что в Стратегии все сценарии предполагают приоритет внутреннего рынка и первоочередное решение задач полноценного хлебофуражного обеспечения населения, на практике, как минимум в краткосрочной перспективе, экспорт остается основным способом стимулировать дальнейшее наращивание производства зерна в стране. Экспорт является эффективным инструментом санации внутреннего зернового рынка, который активно использовался и развивался в России [5]. Однако пока сохраняется сильная зависимость эффективности российского экспорта от ценовой конъюнктуры на мировом рынке. Получается, что при падении мировой цены и росте появляется угроза получения избыточного профицита на внутреннем рынке, емкость которого увеличить не получится, тем более в короткий срок.

На данном этапе состояние цен на мировом рынке позволяет рассчитывать на благоприятные условия экспорта пшеницы для российских компаний - на крупных биржах США (основного конкурента России по экспорту) мартовские котировки находятся на уровне прошлого года, а к маю цена, хоть и не значительно, но увеличивается. С другой стороны, увеличиваются цены на российском зерновом рынке, снижая соотношения внутренних и внешних цен на зерно, что сдерживало в первую половину сезона развитие экспорта за счет удаленных регионов, ориентированных на внутренний рынок, и более активно задействующихся для экспорта, когда ресурсы традиционных экспортных зерновых регионов подходят к концу.

В целом, краткосрочный прогноз экспорта зерна в сезоне 2019/20 год можно оценивать на 
уровне не менее 45 млн. т из-за высокого урожая и снижения внутренних потребностей. В первой половине сезона уже было экспортировано 25 млн. т, хотя это меньше показателя прошлого года, т.е. текущий объем экспорта ниже своего потенциала. Одной из причин снизившей экспортный потенциал стало снижение уровня воды в Таганрогском заливе Азовского моря, изза чего прекратилось судоходство в этом районе. Это отдельный эпизод, который подчеркивает, что по-прежнему существует острая потребность в улучшении логистической инфраструктуры для повышения эффективности экспорта [6]. Значительной угрозой в краткосрочной перспективе для наращивания экспортного потенциала является тенденция сокращения соотношения между экспортными и внутренними ценами, в результате чего текущие остатки в экспортно-ориентированном южном мезорегионе уже меньше, чем в прошлые годы [2]. Также на экспортные товары негативно повлияло укрепление рубля - в августе курс доллара США составлял 65-66 руб., а в декабре он упал 62 руб., поэтому экспортеры вынуждены повышать цены, тогда как на внутреннем рынке цены не снижаются.

Тем не менее, многими экспертами и Минсельхозом ожидается активизация экспортных процессов в следующем полугодии, в том числе и потому что обычно конкурентоспособность российской пшеницы и ячменя в этот период выше, чем у ряда конкурентов. Уже сейчас за январь произошла девальвация рубля до курса 64 рубля/долл. и тенденция падения курса российской валюты продолжится, что позитивно для экспортеров. Положительными сигналами также могут служить прогнозы урожая в Северном полушарии и сохранение напряженной геополитической обстановки на Ближнем Востоке, который является одним из основных рынков для России. К перспективным факторам для поставок российского зерна в этот региона служат следующие события: Саудовская Аравия открыла для российского зерна свой рынок, емкость которого свыше 3 млн. т; повышение качества российского зерна, которое позволяет расширить его рыночную нишу в Турции; Иран подписал меморандум с Казахстаном и Россией о поставках до 3 млн. т пшеницы. Поэтому, если в первой половине сезона Россия теряла позиции на мировом рынке, то в ближайшей перспективе сокращение прогноза урожая озимой пшеницы во Франции и площади посевов зерновых в США при хорошем состоянии озимых в России является также положительным сигналом к увеличению экспорта зерна в сравнении с предыдущим годом.

Минсельхозом также высоко оцениваются перспективы зернового экспорта в краткосрочном периоде, поэтому как вариант регулирования рассматривается возможность применения квоты в размере 20 млн. т в период с января по июнь 2020 года. Инструмент квотирования применяется в целях обеспечить зерном внутренние потребности страны. С одной стороны, экспорт вряд ли значительно превысит уровень в 45 млн. т, что не создает угрозы национальной продовольственной безопасности в сложившихся условиях, а механизм квот обещается быть максимально прозрачным и не создавать преференции отдельным компаниям. С другой стороны, это в любом случае негативный сигнал рынку, который ставит вопрос при стратегических планах компаний по налаживанию партнерских отношений с зарубежными партнерами и развитию инфраструктуры хранения и логистики, подталкивая их к уходу с рынка.

В это же время фактически создан холдинг в лице банка ВТБ, который планирует стать крупнейшим экспортеров российского зерна. Такой крупный бизнес может решить проблему форвардных и фьючерсных контрактов на пшеницу, а концентрация ресурсов позволяет повысить доходность экспорта при неблагоприятной ценовой конъюнктуре на мировом рынке. Однако вместе с этим создание такой компании приведет к монополизации и снижению конкуренции на рынке, что в стратегическом периоде скажется на эффективности производства зерна. Более того, имеется отрицательный опыт функционирования таких монопольных компаний на рынке наших конкурентов по экспорту зерна в Австралии и Канаде, а также отечественный опыт «Объединенной зерновой компании» также не является успешным примером.

Следует помнить, что неожиданные изменения в регулирование зернового рынка негативно влияли на инвестиционный климат в отрасли. Также идея квотирования идет в разрез с майским указом президента России, в котором ставится задача увеличения агроэкспорта, а зерно является его важной составляющей. Квота, безусловно, является более прозрачным и формализованным инструментом регулирования 
рынка, чем ручное управление, но это в любом случае не является защитой от форс-мажорных угроз продовольственной безопасности страны. Применение квоты следует осуществлять в контексте прогноза зернового баланса в начале сезона, чтобы компании-участники экспорта могли строить тактику в краткосрочной перспективе без ущерба для их стратегических проектов.

Стабильность системы государственного регулирования зернового рынка определяется возможностью точной вариативной оценкой среднесрочных перспектив по производству и внутреннему потреблению зерна, в то время как экспорт будет являться инструментом санации, обеспечивая благоприятную ценовую конъюнктуру. Мы исходим из трех вариантов изменения емкости спроса на зерно на внутреннем рынке: оптимистичный вариант предполагает увеличение спроса за счет динамичного развития животноводства; реалистичный - со- хранение текущего уровня потребления; пессимистичный - незначительное сокращение в размерах наметившегося в последний год тренда. Прогнозный ориентир по срокам для такой ситуации будет характерен при сохранении технологии и условий возделывания зерновых культур, т.е. минимум на ближайшие 5 лет, с учетом сложившейся нестабильности урожаев зерна. Согласно последним урожаям зерновых культур с вероятностью 95\% отклонение от уровня 2019 года не превысит 10 млн. т зерна, что дает 6 вариантов развития ситуации с учетом добавления форс-мажорного сценария, характеризующего влияние неблагоприятных природно-климатических условий. В зависимости от заданных параметров экспорт может варьироваться от 13 до 53 млн. т в ближайшем году с учетом сохранения текущего уровня запасов зерна (таблица 3).

Высокий экспортный потенциал последних лет определяется сверхудачным урожаем 2017

\section{Таблица 3. Прогноз основных параметров развития зернового подкомплекса России в краткосрочный} период

\begin{tabular}{|c|c|c|c|}
\hline $\begin{array}{c}\text { Сценарий развития } \\
\text { ситуации }\end{array}$ & $\begin{array}{c}\text { Валовой сбор зерновых, } \\
\text { млн. т }\end{array}$ & $\begin{array}{c}\text { Внутреннее потребление } \\
\text { зерна, млн. т }\end{array}$ & Экспорт зерновых, млн. т \\
\hline \multicolumn{4}{|c|}{ Резкий прирост урожая зерновых относительно уровня 2019 года на 10 млн. т } \\
\hline Оптимистичный & 130,0 & 81,0 & 49,0 \\
\hline Базовый & 130,0 & 78,5 & 51,5 \\
\hline Пессимистичный & 130,0 & 77,0 & 53,0 \\
\hline \multicolumn{4}{|c|}{ Прирост урожая зерновых относительно уровня 2019 года на 5 млн. т } \\
\hline Оптимистичный & 125,0 & 81,0 & 44,0 \\
\hline Базовый & 125,0 & 78,5 & 46,5 \\
\hline Пессимистичный & 125,0 & 77,0 & 48,0 \\
\hline \multicolumn{4}{|c|}{ Сохранение уровня 2019 года с погрешностью в 2 млн. т } \\
\hline Оптимистичный & 122,0 & 81,0 & 41,0 \\
\hline Базовый & 120,0 & 78,5 & 42,5 \\
\hline Пессимистичный & 118,0 & 77,0 & 41,0 \\
\hline \multicolumn{4}{|c|}{ Сокращение урожая зерновых относительно уровня 2019 года на 5 млн. т } \\
\hline Оптимистичный & 115,0 & 81,0 & 34,0 \\
\hline Базовый & 115,0 & 78,5 & 36,5 \\
\hline Пессимистичный & 115,0 & 77,0 & 38,0 \\
\hline \multicolumn{4}{|c|}{ Резкое снижение урожая зерновых относительно уровня 2019 года на 10 млн. т } \\
\hline Оптимистичный & 110,0 & 81,0 & 29,0 \\
\hline Базовый & 110,0 & 78,5 & 31,5 \\
\hline Пессимистичный & 110,0 & 77,0 & 33,0 \\
\hline \multicolumn{4}{|c|}{ Неурожай из-за форс-мажорных условий с падением на 20-30 млн. т } \\
\hline Оптимистичный & 100,0 & 81,0 & 19,0 \\
\hline Базовый & 95,0 & 78,5 & 16,5 \\
\hline Пессимистичный & 90,0 & 77,0 & 13,0 \\
\hline
\end{tabular}

Источник: составлено автором 
года, однако переходные запасы сокращаются, поэтому регулирование экспорта через квотирование вполне обосновано, так как неконтролируемое желание экспортеров увеличить свои доходы может пагубно сказаться на удовлетворении внутренних потребностей. Однако квотирование и более жесткие инструменты регулирования экспорта зерна могут подорвать его эффективность на мировом рынке, что в дальнейшем затруднит его применение как инструмента санации внутреннего зернового рынка и стимула для наращивания урожая через инновационные факторы. В краткосрочной перспективе лучшими решениями будут те, которые позволят сохранить относительно высокие цены на российском зерновом рынке, формируя естественный рыночный фактор, определяющий нецелесообразность вывоза зерна за границу, что можно в определенной степени увидеть уже и в 2019 году. Именно через внутренние цены будет можно оперативно регулировать увеличение потоков зерна на вывоз за рубеж из регионов, которые изначально менее ориентированы на экспорт, при получении там урожая, превышающего ожидаемый уровень. Также обязательно дальнейшее развитие логистической инфраструктуры, создающей альтернативные каналы движения зерна на экспорт с меньшими трансакционными издержками.

\section{Библиографический список}

1. Долгосрочная стратегия развития зернового комплекса Российской Федерации до 2025 и на перспективу до 2035 г. Министерство сельского хозяйства РФ. [Электронный ресурс]. Режим доступа: http://mcx.ru/ upload/iblock/04c/04c91c2c72fbd773540ec908f9410edd.pdf (Дата обращения 13.02.2020 г.).

2. Аналитики пересматривают прогнозы экспорта зерна // Официальный сайт www.agroinvestor.ru [Электронный ресурс] - режим доступа: https://www.agroinvestor.ru/analytics/news/32973-analitiki-peresmatrivayutprognozy-eksporta-zerna/

3. Зюкин Д.А. Формирование стратегии развития зернопродуктового подкомплекса АПК как необходимого элемента успешной реализации политики импортозамещения продовольствия // Региональный вестник. 2018. № 6 (15). С. 31-33.

4. Зюкин Д.А. К вопросу выбора приоритетов в путях развития зернопродуктового подкомплекса и наращивания урожаев зерна // Региональный вестник. 2019. № 19 (34). С. 47-49.

5. Зюкин Д.А. Развитие экспортного потенциала зернового хозяйства России // Экономика сельскохозяйственных и перерабатывающих предприятий. 2019. № 1. С. 58-61.

6. Зюкин Д.А. Развитие инфраструктуры хранения зерна как направление оптимизации процессов межрегионального обмена // Региональный вестник. 2019. № 23 (38). С. 67-69. 